Results: of the 64 patients included in the study, 59 (92.2\%) were women and $5(7.8 \%)$ men, mean age $57.55 \pm 9.42$ years. After 6 months, 7 patients were declared nonresponders, 38 achieved a moderate response and 19 good response.

Following baseline COMP titres and the EULAR response at 6 months, general tests identified significant differences between groups. Lower baseline titres had predictive value for achieving a good response $(746.04 \pm 130.095 \mathrm{ng} / \mathrm{ml})$ comparing with moderate responders $(1032.8 \pm 188.671 \mathrm{ng} / \mathrm{ml})$ and nonresponders (1042.2 $\pm 181.717 \mathrm{ng} / \mathrm{ml}, \mathrm{p}=0.0000$ ).

After 12 months 11 patients achieved moderate response, 44 a good response and just 1 patient was declared nonresponder. At this visit, even if we didn't find significant differences between baseline COMP titres and the EULAR response $(p=0.1430)$, we observed lower baseline titres for good responders $(917.8 \pm 219.943 \mathrm{ng} / \mathrm{ml})$ versus moderate responders $(1042.7 \pm 193.117 \mathrm{ng} / \mathrm{ml})$. Grouping patients in 2 categories (responders/nonresponders) there were no differences between groups at 6 months $(937.27 \pm 218.106 \mathrm{ng} / \mathrm{ml}$ versus $1042.2 \pm 181.717 \mathrm{ng} / \mathrm{ml}, \mathrm{p}=0.227)$ or 12 months $(942.82 \pm 219.025 \mathrm{ng} / \mathrm{ml}$ versus $896.5 \pm 0.000 \mathrm{ng} / \mathrm{ml}, \mathrm{p}=0.9753$ ).

Following the status pretreatment of COMP and EULAR response at 6 months, we identified differences between groups $(p=0,0001)$, all 7 patients declared nonresponders were COMP positive and only $13 / 19(68.4 \%)$ of good responders were tested positive. At 12 months there were no differences between pretreatment status of COMP and response to treatment $(p=0.2805)$.

Regarding the evolution of serum levels, we noticed a decrease statistically significant from baseline $(948.75 \pm 215.683 \mathrm{ng} / \mathrm{ml})$ to 12 months $(740.88 \pm 227.04$ $\mathrm{ng} / \mathrm{ml}, \mathrm{p}=0.0000$ )

Conclusions: COMP could be one of the biomarkers for identifying pretreatment the patients who will respond to biologic therapy in Rheumatoid Arthritis. References:

[1] Chaves Chaparro LM, Salvatierra Ossorio J, Raya Álvarez E Reumatol Clin. 2011 Mar-Apr; 7(2):141-4.

[2] Morozzi G, Fabbroni M, Bellisai F, Cucini S, Simpatico A, Galeazzi MClin Rheumatol. 2007 Aug; 26(8):1335-8.

Disclosure of Interest: None declared

DOI: 10.1136/annrheumdis-2017-eular.1241

\section{AB0377 SWITCHING FROM BIO-ORIGINAL ETANERCEPT TO BIOSIMILAR ETANERCEPT SB4: PATIENT ACCEPTABILITY AND OUTCOMES IN THE REAL WORLD}

C. Holroyd $^{1}$, D. Wallis ${ }^{1}$, S. Bennett ${ }^{1}$, P. Clayton ${ }^{1}$, C.J. Edwards ${ }^{2}$. ${ }^{1}$ Rheumatology; ${ }^{2}$ NIHR Wellcome Trust Clinical Research Facility, University Hospital Southampton, Southampton, United Kingdom

Background: A number of studies have demonstrated the efficacy of biosimilar therapies including SB4 (a biosimilar-etanercept). However, real world data of the process of switching, acceptability to patients, efficacy and safety is lacking.

Objectives: To obtain real world data of the acceptability and outcomes of patients with severe (eligible for TNFi therapy as defined by UK NICE) rheumatoid arthritis (RA), psoriatic arthritis (PsA) and ankylosing spondylitis (AS) who switch from bio-original etanercept (boDMARD-ETN) to the bsDMARD etanercept SB4 (bsDMARD-ETN).

Methods: Adult patients, with RA, PsA \& AS, currently enrolled in the SMaRT study and switching from boDMARD-ETN to bsDMARD-ETN were followed for 6 months. Primary outcome was change in DAS28, PsARC response or BASDAI following switching. Additional outcomes included; \% change of remission rate, HAQ-DI, CRP or ESR levels, patient satisfaction, PDUS and SAEs leading to discontinuation. All patients had severe disease and were receiving boDMARDETN as per local guidelines of UK NICE. Analysis was performed in a similar way to a cross-over RCT trial design where patients act as their own control with the experience in the 6 and 12 months prior to switching used as the control for experience after switching.

Patient education and support during the switch included: rheumatologist face to face discussion, letter giving details of the switch and bsDMARD-ETN information sheet, patients invited to discuss switch in clinic, helpline number with patients advised to call for further information or to report adverse events (AEs), routine review in clinic 3 months after switching, and then 6 monthly thereafter or more often if clinically necessary.

Results: Following the education and support programme $99 \%$ of patients agreed to switch to bsDMARD-ETN (one declined due to concerns about allergic reactions to previous therapies). To date 92 patients have switched from boDMARD-ETN to bsDMARD-ETN and been followed up for more than 6 months (58 RA, 15, AS, 16 PSA and 4 enteropathic arthritis; mean age 55.9 (14.9) yrs, (56 female, 36 male), mean disease duration 16.8 (10.9) yrs, duration on boDMARD-ETN before switch mean 4.85 (3.92) yrs and duration since switch 204.1 (51.4) days. After 6 months following the switch 91\% of patients using bsDMARD-ETN have continued with mean last DAS28 - 2.67 (1.32) for RA patients and mean last BASDAI - 4.58 (2.47). Following the switch 8 patients stopped bsDMARD-ETN after mean of 93.6 (56.4) days, the reasons for this were $7 / 8$ clinician/patient determined inefficacy ( 6 returned to boDMARD-ETN, 1 switched to certolizumab), $1 / 8$ switched after reporting palpitations and poor concentration. In the control period 6 months before switching 17/110 patients stopped boDMARD-ETN $(85 \%$ continued) including 7 due to primary failure, 7 due to secondary failure, 1 adverse event (AE), 1 patient choice, 1 death (Lung cancer in male ex-smoker with longstanding RA who had received boDMARD-ETN for $10 \mathrm{yrs}$ ).

Conclusions: An education programme prior to switching to a biosimilar TNFi leads to a high uptake by patients. In follow-up of 6 months after switching from boDMARD-ETN to a bsDMARD-ETN there appears to be a low rate of discontinuation due to inefficacy or AEs.

Acknowledgements: Biogen supported this work through an unrestricted grant. Disclosure of Interest: C. Holroyd Speakers bureau: Abbvie, UCB, Roche, Pfizer, D. Wallis: None declared, S. Bennett: None declared, P. Clayton: None declared, C. Edwards Grant/research support from: Abbvie, Roche, Pfizer, Biogen, Speakers bureau: Merk, Abbvie, UCB, Roche, Pfizer, Celgene, Janssen, Celltrion, Lilly DOI: 10.1136/annrheumdis-2017-eular.3672

\section{AB0378 IMPROVED CLINICAL OUTCOMES AND PHYSICAL ACTIVITY IN PATIENTS WITH RHEUMATOID ARTHRITIS TREATED WITH ADALIMUMAB IN CENTRAL AND EASTERN EUROPE}

D. Karateev ${ }^{1}$, C. Codreanu ${ }^{2}$, B. Rojkovich ${ }^{3}$, M. Hojnik ${ }^{4}$, E. Smirnova ${ }^{5}$. ${ }^{1}$ Nasonova Research Institute of rheumatology, Moscow, Russian Federation; 2 "Dr. Stoia" Center for Rheumatic Diseases, University of Medicine and Pharmacy "Carol Davila", Bucharest, Romania; ${ }^{3}$ Hospital of Hospitaller Brothers of St. John of God, Budapest, Hungary; ${ }^{4}$ AbbVie, Ljubljana, Slovenia; ${ }^{5}$ AbbVie, Moscow, Russian Federation

Background: Although physical activity has known positive impacts upon pain, disease activity and functional status in patients with rheumatoid arthritis (RA), very little is known about physical activity in patients with RA on biologic therapy. Objectives: To evaluate the effect of adalimumab treatment on physical activity and relationship with improvements in disease activity and physical function in patients with RA in routine clinical practice.

Methods: This was a 52-week multi-center, post-marketing observational study conducted in 7 countries in Central and Eastern Europe (CEE). Eligible RA patients were prescribed originator adalimumab according to the local practice; visits were performed approximately 3 months apart. Physical activity was assessed by validated Short QUestionnaire to ASsess Health-enhancing physical activity (SQUASH)[1,2], which measures habitual physical activity across four domains: commuting, leisure time and sport, household, work and school. RA disease activity was assessed by DAS28 and physical function by HAQ-DI; clinical remission (REM) and low disease activity (LDA) were defined as DAS28<2.6 and $<3.2$, respectively. Descriptive statistical analyses were performed, observed data are presented.

Results: 462 patients were enrolled and 255 patients completed the study. Mean age was $53.9( \pm 12.1)$ yrs; $82.2 \%$ of enrolled patients were female; average disease duration was $7.8( \pm 7.5)$ yrs. DAS28 decreased from $6.1( \pm 1.1)$ at baseline to $2.9( \pm 1.0)$ at study end, whereas the mean HAQ-DI from $1.6( \pm 0.6)$ to 0.7 $( \pm 0.5)$. The proportion of patients in LDA and REM at study end was $56.0 \%$ and $31.1 \%$, respectively. Total SQUASH score increased from $4772( \pm 4132)$ to 6104 $( \pm 4921)$, representing $28 \%$ improvement in overall physical activity. The largest score improvements were seen in the SQUASH domains of leisure time and sport (by $43 \%$ ), followed by household activities and activities at work and school (each by $19 \%$ ). The correlations between the total SQUASH score and its subscores with DAS28 were weak both at baseline and study end. A significant correlation between the total SQUASH and HAQ-DI scores was seen at baseline $(r-0.30)$, but not at the study end $(r-0.22)$. Correlations between SQUASH subscores and HAQ-DI were not significant. The percentage of work disabled subjects decreased from $22 \%$ to $17 \%$. According to linear regression analysis, sociodemographic factors did not substantially influence habitual physical activity.

Conclusions: Treatment with adalimumab in clinical practice in CEE resulted in clinically meaningful improvements in disease activity and physical function as well as improvements in physical activity. The correlation between the scores for disease activity, physical function and physical activity were however poor and there was no clear influence of the standard sociodemographic factors on physical activity.

\section{ences:}

[1] Wendel-Vos WGC. et al. J Clin Epidemiol 2003; 56: 1163-9.

[2] Campbell N. et al. J Phys Act Health. 2016;13(2):154-8.

Acknowledgements: Funding: The design, study conduct, and financial support for the clinical trial were provided by AbbVie. AbbVie participated in the interpretation of data, drafting, review, and approval of the abstract.

Disclosure of Interest: D. Karateev Grant/research support from: Pfizer, Consultant for: Pfizer, Tirupharm, Biocad, Egis, R-Pharm, Novartis, Speakers bureau: Abbvie, Bristol Myers Squibb, Pfizer, Roche, Tirupharm, Biocad, R-Pharm, Novartis, Egis, MSD, UCB, C. Codreanu Grant/research support from: AbbVie, Amgen, BMS, Egis, MSD, Pfizer, Roche, Sanofi, UCB, Consultant for: AbbVie, Amgen, Angellini, Astra Zeneca, BMS, Egis, MSD, Pfizer, Richter, Roche, Sanofi, Servier, Teva, UCB, Zentiva, Speakers bureau: AbbVie, Amgen, Angellini, Astra Zeneca, BMS, Egis, MSD, Pfizer, Richter, Roche, Sanofi, Servier, Teva, UCB, Zentiva, B. Rojkovich Grant/research support from: AbbVie, Amgen, Novartis, Sanofi, UCB, Consultant for: Abbvie, Pfizer, Roche, Speakers bureau: Abbvie, Pfizer, Roche, M. Hojnik Employee of: AbbVie, E. Smirnova Employee of: AbbVie

DOI: 10.1136/annrheumdis-2017-eular.4034 